\title{
Efficacy of brain natriuretic peptide vs nicorandil in preventing contrast-induced nephropathy: a network meta- analysis
}

\author{
Ziwei Mei $^{1}$, Songmei Luo ${ }^{1}$, Peipei Chen ${ }^{1}$, Qiankun Zhang ${ }^{2}$, Limei Zhou ${ }^{2}$, Chaoyong Zhu ${ }^{2}$, Hong Zhu ${ }^{\text {Corresp., }}{ }^{2}$, Lie Jin \\ Corresp. 2 \\ 1 Pharmacy Department, Lishui municipal central hospital, Lishui, Zhejiang, China \\ 2 Nephrology Department, Lishui municipal central hospital, Lishui, Zhejiang, China \\ Corresponding Authors: Hong Zhu, Lie Jin \\ Email address: Iszxyyzhuhong@163.com, lijie1022@163.com
}

This study aimed to conduct a network meta-analysis (NMA) to compare the efficacy of brain natriuretic peptide (BNP) vs nicorandil for preventing contrast-induced nephropathy (CIN). Databases of Pubmed, Cochrane, Embase, Web of Science were searched by keywords for eligible studies of randomized controlled trials investigating different agents (BNP, nicorandil, nitroglycerin, intravenous saline) for preventing CIN. The outcomes included a change in serum creatinine level at 48 hours and the incidence of CIN after percutaneous coronary intervention (PCI) or coronary angiography (CAG). A total of 13 studies with 3462 patients were included. Compared with intravenous saline alone, except for nitroglycerin (odds ratio [OR]: 1.02, 95\% confidence interval [CI]: 0.36, 2.88), the other drugs significantly reduced the CIN incidence with OR of $0.35(95 \% \mathrm{Cl}: 0.24,0.51)$ for BNP, $0.52(0.29,0.94)$ for usual-dose nicorandil, $0.28(0.19,0.43)$ for double-dose nicorandil. BNP and double-dose nicorandil significantly decreased the change of serum creatinine (SCr) levels with mean difference (MD) of -6.98, (-10.01, -3.95) for BNP, -8.78, (-11.63, -5.93) for double-dose nicorandil. No significant differences were observed in the change of $\mathrm{SCr}$ levels for nitroglycerin $(-4.97,[-11.46,1.52])$ and usual-dose nicorandil (-2.32, [-5.52, $0.89]$ ) compared with intravenous saline alone. For double-dose nicorandil, the CIN incidence and the change of $\mathrm{SCr}$ level in group of 4-5 days treatment course were more than group of less than or equal to $24 \mathrm{~h}$ treatment course (OR of 1.48, [0.63-3.46] and MD of $2.48,[-1.96,6.91])$. In conclusion, BNP and double-dose nicorandil can have effect on preventing the incidence of $\mathrm{CIN}$ and double-dose nicorandil performed better effect than BNP. In double-dose nicorandil groups, the course of less than or equal to $24 \mathrm{~h}$ before and after procedure performed better efficacy than the course of 4-5 days. 
1 Efficacy of brain natriuretic peptide vs nicorandil in preventing contrast-induced

2 nephropathy: a network meta-analysis

3 Ziwei MEI ${ }^{1}$, Songmei $\mathrm{LUO}^{1}$, Peipei $\mathrm{CHEN}^{1}$, Qiankun ZHANG ${ }^{2}$, Limei ZHOU ${ }^{2}$, Chaoyong ZHU², HONG

$4 \mathrm{ZHU}^{2 *}$, LIE JIN ${ }^{*}$

$5 \quad$ IPharmacy Department, Lishui Municipal Central Hospital, Lishui, Zhejiang, China

$6 \quad{ }^{2}$ Nephrology Department, Lishui Municipal Central Hospital, Lishui, Zhejiang, China

8 Ziwei Mei, Department of Pharmacy, Lishui Municipal Central Hospital, 323000 Lishui, China. Tel:

9 17858199601.e-mail: 1szxyymzw@163.com

10 Corresponding Author: Hong Zhu, Department of Nephrology, Lishui Municipal Central Hospital, 323000,

11 Lishui, China. Tel: 13506500270. e-mail: 1szxyyzhuhong@163.com; Lie Jin, Department of Nephrology, Lishui

12 Municipal Central Hospital, 323000, Lishui, China. Tel:05782285229, e-mail: lijie1022@163.com

14 Abstract

15 This study aimed to conduct a network meta-analysis (NMA) to compare the efficacy of brain 16 natriuretic peptide (BNP) vs nicorandil for preventing contrast-induced nephropathy (CIN). Databases of Pubmed, Cochrane, Embase, Web of Science were searched by keywords for eligible studies of randomized controlled trials investigating different agents (BNP, nicorandil, nitroglycerin, intravenous saline) for preventing CIN. The outcomes included a change in serum creatinine level at 48 hours and the incidence of CIN after percutaneous coronary intervention (PCI) or coronary angiography (CAG). A total of 13 studies with 3462 patients were included. Compared with intravenous saline alone, except for nitroglycerin (odds ratio [OR]: 1.02, 95\% confidence interval [CI]: $0.36,2.88$ ), the other drugs significantly reduced the CIN incidence with OR of 0.35 (95\%CI: $0.24,0.51)$ for BNP, $0.52(0.29,0.94)$ for usual-dose nicorandil, $0.28(0.19$, 0.43) for double-dose nicorandil. BNP and double-dose nicorandil significantly decreased the change of serum creatinine (SCr) levels with a mean difference (MD) of $-6.98,(-10.01,-3.95)$ for BNP, -8.78, (-11.63, -5.93) for double-dose nicorandil. No significant differences were observed 
in the change of SCr levels for nitroglycerin $(-4.97,[-11.46,1.52])$ and usual-dose nicorandil ($2.32,[-5.52,0.89])$ compared with intravenous saline alone. For double-dose nicorandil, the CIN incidence and the change of SCr level in a group of 4-5 days treatment course were more than group of less than or equal to $24 \mathrm{~h}$ treatment course (OR of 1.48, [0.63-3.46] and MD of 2.48, [$1.96,6.91])$. In conclusion, BNP and double-dose nicorandil can affect preventing the incidence of CIN and double-dose nicorandil performed better effect than BNP. In double-dose nicorandil groups, the course of less than or equal to $24 \mathrm{~h}$ before and after the procedure performed better efficacy than the course of 4-5 days.

Abbreviations: NMA, network meta-analysis; BNP, brain natriuretic peptide; CIN, contrastinduced nephropathy; PCI, percutaneous coronary intervention; CAG, coronary angiography; MD, mean differences; 95\%CI, 95\% confidence interval; OR, odds ratio; RCT, randomized controlled trial; PRISMA, Preferred Reporting Items for Systematic Reviews and Meta-Analyses; SCr, serum creatinine; SUCRA, surface under the cumulative ranking curve; eGFR, estimated glomerular filtration rate; IF, Inconsistency factor.

Keywords: Contrast-induced nephropathy, Brain natriuretic peptide, Nicorandil, Meta-analysis

\section{Introduction}

PCI or CAG is a common method for coronary heart disease treatment and diagnosis. However, the application of contrast agents for patients undergoing CAG or PCI usually induces CIN. CIN refers to abrupt damage in renal function after the administration of contrast agents ${ }^{[1-3]}$. $\mathrm{CIN}$ is a serious complication featured by the deterioration of renal function which may lead to water-sodium retention aggravating heart failure and drug accumulation increasing adverse drug reaction ${ }^{[4]}$. In the long term, it will induce damage to cardiovascular system and digestive system. With the increased application of contrast agents for radiation diagnosis and interventional therapy, the rate of CIN continues to rise. It has been reported that the incidence of CIN varies 
55

from $2 \%$ to $50 \%$, it likely more occurred in patients with risk factors, such as pre-existing renal impairment, diabetes mellitus, congestive heart failure, advanced age, and hypertension ${ }^{[5]}$. CIN is the third most common cause of hospital-acquired acute kidney injury prolonging hospitalization and increasing some poor outcomes, such as dialysis and cardiovascular disease ${ }^{[6-8]}$. Therefore, CIN has become one of the important issues affecting the survival and prognosis of patients.

Nowadays, there is no effective method to treat CIN, therefore more and more studies have been conducted to explore methods for preventing the occurrence of $\mathrm{CIN}^{[9,10]}$. A large number of randomized controlled trials (RCTs) have demonstrated pharmacological drugs could prevent the incidence of CIN. These years, prostaglandin analogues and BNP analogues are applied to prevent the CIN in the PCI and CAG. Some RCTs showed BNP and nicorandil interventions could reduce the incidence of CIN and SCr levels in the PCI and $\mathrm{CAG}^{[11,12]}$. However, there was no study evaluating and comparing the efficacy of BNP and nicorandil on preventing CIN. This study conducted an NMA of RCTs to, directly and indirectly, compare the efficacy of BNP vs nicorandil for preventing CIN in PCI or CAG.

\section{Methods}

The protocol of this NMA has been registered on the International Prospective Register of Systematic Review with a registration number CRD42021278424. We reported this NMA based on the Preferred Reporting Items for Systematic Reviews and Meta-Analyses (PRISMA) statement for NMA.

\subsection{Data sources and searches}

Two reviewers (MZW and ZQK) independently searched the literature and disagreements were resolved by consensus-based discussion. We searched extensive literature from Pubmed, Cochrane, Embase, Web of Science, and clinicaltrials.gov databases. The deadline for publication for inclusion in the meta-analysis was August 2021. Our search terms and search strategy were ((nicorandil) OR (brain natriuretic peptide)) AND ((coronary angiography) OR (percutaneous coronary intervention)); (contrast-induced nephropathy) AND ((nicorandil) OR (brain natriuretic peptide)). In addition, references included to related meta-analysis were viewed as potential 
82

studies.

2.2 Study selection

The final studies were selected by the following inclusion criteria: (1) full-RCTs; (2) evaluating the efficacy of CIN prevention; (3) all patients following PCI or CAG; (4) hydration is the co-intervention in the treatment and control groups; (5) reported sufficient data and at least one of the following outcomes: the incidence of CIN, SCr levels.

Studies were excluded according to the following features: (1) non-RCTs; (2) duplicate publication; (3) animal studies; (4) lacking data about the incidence of CIN and serum creatinine level.

\subsection{Endpoint}

The primary outcome was CIN defined by an increase in $\mathrm{SCr}$ of $>0.5 \mathrm{mg} / \mathrm{dL}$ or $>25 \%$ from baseline within 48hours after PCI or CAG, the definition of CIN reported by the included study was accepted. The secondary endpoint was the SCr level change, before and after the procedure. If the SCr value was reported at multiple time points, we extracted it at $48 \mathrm{~h}$ after the procedure.

\subsection{Data Extraction and Quality Assessment}

Three reviewers (ZLM, CPP, and ZCY) independently extracted data from original trial reports in a standardized form. By discussion with a third reviewer (JL), discrepancies were settled. The characteristics of the enrolled studies in each group including first author, publication date, country, sample size, baseline characteristics of the patients, the incidence of CIN, SCr level were extracted. Each included study was assessed by the risk of bias evaluated tool from the Cochrane Handbook for Randomized Controlled Trials. This assessment was completed independently by two investigators (MZW and $\mathrm{ZH})$ and disagreements were discussed with a third reviewer and resolved through consensus.

\subsection{Data analysis}

We applied network meta-analysis to estimate the treatment effect of pharmacological interventions by the $\mathrm{OR}$ for the incidence of $\mathrm{CIN}$ and $\mathrm{MD}$ for $\mathrm{SCr}$ level at $48 \mathrm{~h}$ after the procedure with a 95\%CI. The treatment hierarchy was summarized and reported according to surface under 
the cumulative ranking curve (SUCRA) and mean ranks. SUCRA was presented as a percentage and used to determine the probability of a treatment being the most effective, without uncertainty on the outcome. The higher probability viewed as the best intervention was the larger surface area under the curve.

Inconsistency was assessed by global inconsistency, loop-specific and node-splitting approach between direct and indirect evidence. In global inconsistency, $P>0.05$ was considered there was no statistical significance about heterogeneity among the evidence. For the loop-specific approach, the extent of bias and inconsistency was evaluated by the inconsistency factor (IF). When the IF with a $95 \% \mathrm{CI}$ included 0 , it demonstrated the estimates of treatment effects from direct and indirect evidence are in agreement. For the node-splitting approach, the evidence about certain comparisons was separated into direct and indirect evidence and the result was reported by $P$-value, $P>0.05$ indicated there is no inconsistency. Statistical analysis was performed by STATA 15.0 (Stata Corporation, College Station, Texas, USA).

\section{Results}

\subsection{Study characteristics}

13 RCTs studies were included for analysis after removing the duplicate studies, reviews, non-RCTs, and irrelevant content. The literature search process was shown in Fig 1. The publication year of the included studies ranged from 2014 to 2019. 3462 participants have included totally and female participants accounted for $31.43 \%$. The sample sizes ranged from 128 to 1000 . The information and baseline characteristic of the studies were provided in Table1 and Table2. The 13 RCTs contained the following comparisons: BNP vs hydration $(n=4)$, BNP vs nitroglycerin $(\mathrm{n}=1)$, nicorandil vs hydration $(\mathrm{n}=8)$.

\subsection{Quality of the included studies}

Most of the studies were judged to be at low risk of bias for 6 domains ${ }^{[13-17]}$, according to the Cochrane Collaboration's tool. 8 studies were judged to be at high risk of bias for they were not blinded ${ }^{[18-25]}$. One study was judged to be at high risk of bias for participants were randomized according to the participating centers and the severity of the renal dysfunction (estimated 
136 Glomerular Filtration Rate (eGFR) $\leq 40$ or $>40 \mathrm{~mL} / \mathrm{min})^{[20]}$. The risk of bias assessment of the

137 trials included in this study was presented in Supplement Fig 1.

$138 \quad 3.3$ Network meta-analysis results

139 We assessed the efficacy of five different interventions including intravenous saline, 140 nitroglycerin, BNP, usual-dose nicorandil, double-dose nicorandil for preventing CIN. The 141 network of comparisons for CIN occurrence and the change of SCr level was shown in Fig 2. 142 These RCTs included intravenous saline (11 trials, 1560 participants for CIN; 10 trials, 1431 143 participants for SCr; ), nitroglycerin $(1,59 ; 1,59)$, BNP $(4,734 ; 5,800)$, usual-dose nicorandil (3, $144244 ; 3,286)$, double-dose nicorandil $(6,739 ; 4,508)$.

145 3.4 The incidence of CIN after the procedure

146 Totally 12 RCTs including 3332 participants have evaluated the effect of pharmacological

interventions on the incidence of CIN. The result was shown by forest plots (Figure 3A). Compared with intravenous saline alone, additional administration of nitroglycerin was ineffective for decreasing the CIN incidence (OR, 1.02 [95\%CI: 0.36, 2.88] $(P=0.973)$. Unstatistic significance between nitroglycerin and intravenous saline can be viewed the effect on reducing the CIN incidence was equal to each other. On the contrary, BNP and nicorandil much more significantly decreased the CIN than intravenous saline alone (OR of 0.35 (95\%CI: $0.24,0.51)$ for BNP $(P<0.001) ; 0.52(0.29,0.94)$ for usual-dose nicorandil $(P=0.031) ; 0.28(0.19,0.43)$ for doubledose nicorandil $(P<0.001)$. It demonstrated pharmacological intervention by BNP or nicorandil can effectively reduce the occurrence of CIN.

The SUCRA was presented in Figure 4A. SUCRA was used to rank the efficacy of the drugs interventions in our study. The SUCRA values provided the hierarchy for five interventions that are $13.3,16.3,76.6,50.9,92.9 \%$ of intravenous saline, nitroglycerin, BNP, usual-dose nicorandil, double-dose nicorandil for the incidence of CIN (Supplement Table 1). According to the SUCRA, we could find double-dose nicorandil had the best efficacy in the CIN occurrence, followed by BNP and usual-dose nicorandil. It concluded double-dose nicorandil was superior to BNP and usual-dose nicorandil was inferior to BNP inefficacy of reducing CIN incidence. 
3.5 Efficacy of SCr level after the procedure

Related to the change of the SCr level, 11 RCTs including 3084 patients were available to the network meta-analysis. The result was shown by forest plots (Figure 3B). Although administration of nitroglycerin or usual-dose nicorandil decreased the SCr levels with MD (-4.97, [-11.46, 1.52] $(P=0.133)$ for nitroglycerin and $-2.32,[-5.52,0.89](P=0.156)$ for usual-dose nicorandil), there were no statistical differences for nitroglycerin and usual-dose nicorandil compared with intravenous saline. We can confirm that additional administration of nitroglycerin or usual-dose nicorandil except for hydration can't significantly decrease the SCr level in PCI or CAG. For BNP and double-dose nicorandil, we discovered these two interventions could significantly reduce the SCr level with MD (-6.98, [-10.01, -3.95] $(P<0.001)$ for BNP, -8.78, [-11.63, -5.93] $(P<0.001)$ for double-dose nicorandil).

The SUCRA values provide the hierarchy for five interventions that are $3.5 \%, 52.4 \%, 73.4 \%$, $29.5 \%, 91.2 \%$ of intravenous saline, nitroglycerin, BNP, usual-dose nicorandil, double-dose nicorandil for reducing the change of SCr levels (Figure 4B and Supplement Table 2). We concluded BNP and double-dose nicorandil can significantly decrease the SCr level in PCI or CAG. It is not recommended to apply nitroglycerin or usual-dose nicorandil to prevent CIN because of ineffectiveness in reducing SCr level.

3.6 NWA of different courses of double-dose nicorandil intervention

We divided the RCTs of double-dose nicorandil into two groups according to the treatment course for comparing the efficacy in reducing the $\mathrm{CIN}$ incidence and the change of SCr level. One group administrated double-dose nicorandil for the course of less than or equal to $24 \mathrm{~h}$, the other group used double-dose nicorandil for 4-5 days. Five RCTs were included in the network of analyzing the CIN incidence and Four RCTs were available to discuss the change of SCr level. We can discover the CIN incidence and the change of SCr level in a group of 4-5 days course were more than a group of less than or equal to $24 \mathrm{~h}$ course by OR and MD (1.48, [0.63-3.46]; 2.48, [1.96, 6.91]) (Supplement Fig. 2).

The SUCRA values provided the hierarchy for two-course groups that are $90.7,59.3 \%$ for 
the group of less than or equal to $24 \mathrm{~h}$ course and a group of 4-5 days course in the CIN incidence and are $93.5 \%, 56.5 \%$ for the group of less than or equal to $24 \mathrm{~h}$ course and a group of 4-5 days course in the change of SCr level (Supplement Fig 3, Supplement Table 3 and 4). It demonstrated the efficacy of preventing CIN occurrence in a group of less than or equal to $24 \mathrm{~h}$ course was better than a group of 4-5 days course before and after the procedure.

3.7 Heterogeneity and inconsistency assessment

All RCTs were tested for the inconsistency assessed by global inconsistency, loop-specific and node-splitting approach between direct and indirect evidence. In global inconsistency, $P=0.609$ and $P=0.797(>0.05)$ in the analysis of CIN and SCr level were demonstrated there was no statistical significance about heterogeneity among the evidence. For the loop-specific approach, the IF is $0.06(95 \% \mathrm{CI}: 0.00-1.36)$ indicating the treatment effect from direct and indirect evidence are in agreement (Supplement Fig 4). For the node-splitting approach, the results were presented in Supplement Tables 5 and 6. $P$-value $>0.05$ indicated no inconsistency among the direct and indirect comparisons.

\subsection{Small-study effect analysis}

The results of the comparison-adjusted funnel plots indicated that there may not be smallstudy effects for efficacy (Figure 5).

\subsection{Clusterank analysis}

Multi-purpose arrangement of efficacy for five interventions and two different treatment courses on CIN incidence and SCr level was conducted by clustering analysis (Supplement Fig. 5). The best effect intervention was $30 \mathrm{mg}$ daily nicorandil administrated from $12 \mathrm{~h}$ before to $12 \mathrm{~h}$ after the procedure, followed by BNP $(1.5 \mathrm{ug} / \mathrm{kg})$ for $24 \mathrm{~h}$ before the procedure.

\section{Discussion}

There is a high risk of the CIN occurrence caused by the administration of contrast agents for patients undergoing CAG and PCI. Periprocedural hydration is the most common method for intervention the incidence of CIN in clinical practical application. For patients with nondehydration, $500 \mathrm{~mL}$ of water was suggested to drink before the contrast examination. In addition, 
217 within $24 \mathrm{~h}$ contrast exposure administrating $2500 \mathrm{~mL}$ of intravenous saline to sustain a urine 218 generation rate over $1 \mathrm{ml} / \mathrm{kg} / \mathrm{h}^{[26]}$. This method is effective for preventing the incidence of CIN.

219 However, how much the volume of hydration is sufficient to effectively decrease the incidence of 220 CIN hasn't been standardized. In addition, the fluids in periprocedural hydration may aggravate

221

222

223

224

225

226

227

228

229

230

231

232

233

234

235

236

237

238

239

240

241

242

disease conditions for patients with heart failure or edema and increase arrhythmias and short-term death risk in the high-risk patient ${ }^{[27,28]}$. Therefore, researchers effort to study the treatment of various pharmacological agents in preventing the incidence of CIN. It indicated that compared with intravenous saline alone, pharmacological agents intervention has better benefits to reduce the occurrence of CIN.

Currently, more recent interventions about prostaglandin analogues and BNP analogues are confirmed that could prevent the incidence of CIN. It proved BNP have diuretic and natriuretic action by increasing glomerular filtration rate(GFR) ${ }^{[29]}$. This action makes it improving renal hemodynamics and tubular function ${ }^{[30]}$. According to this pharmacological action, several studies have been performed to use BNP to reduce the incidence of CIN in patients undergoing PCI or CAG. Nicorandil is a combination of nicotinamide vitamins and nitrates improving blood flow by opening ATP-sensitive potassium channels and cytoplasmic guanosine cyclase in the kidneys ${ }^{[31,32]}$. It was shown effective in reducing the incidence of CIN. Whereas there is rare guideline recommend them. One reason probably is inadequate study data could determine the effect of prostaglandin analogues and BNP analogues for preventing the CIN. This study is the first network meta-analysis to specifically evaluate the efficacy of nicorandil(prostaglandin analogues) and BNP for preventing the incidence of CIN after PCI and CAG procedures.

In our study, we made some observations from the evidence of 13 RCTs with 3462 patients. First, pharmacological agents of BNP and double-dose nicorandil combined with intravenous saline were identified to be beneficial additionally to reduce the occurrence of CIN and the change of SCr levels at $48 \mathrm{~h}$ after PCI and CAG procedure than intravenous saline alone. Nitroglycerine and usual-dose nicorandil were similar to the intravenous saline alone on the efficacy of preventing CIN. It suggested that the current evidence supports the clinical application of BNP and double- 
244

245

246

247

248

249

250

251

252

253

254

255

256

257

258

259

260

261

262

263

264

265

266

267

268

269

270

dose nicorandil in PCI and CAG. Additional administration of nitroglycerin and usual-dose nicorandil have no obvious effect on preventing the CIN occurrence. Second, between doubledose nicorandil and BNP, double-dose nicorandil had the higher SUCRA ranking in reducing CIN occurrence and SCr levels than BNP. These findings demonstrated double-dose nicorandil has better efficacy than BNP for reducing CIN occurrence and the change of SCr levels. However, for consideration of the adverse drug reaction, we supposed BNP is more suitable to prevent the incidence of CIN than double-dose nicorandil. It indicated that more studies can be performed to explore the potential of BNP in reducing the incidence of CIN in the future. Third, the treatment course of less than or equal to $24 \mathrm{~h}$ of double-dose nicorandil performed better efficacy than the course of 4-5 days before and after the procedure.

The pathophysiology of CIN is may related to the direct nephrotoxic effects and hemodynamic changes induced by contrast agents. Contrast agents have direct cytotoxic effects on renal tubular epithelial cells and vascular endothelial cells. It could increase the level of endothelin and adenosine and decrease the release of NO and prostaglandins that trigger medullary ischemia and decline GFR in the kidney ${ }^{[33]}$. In addition, the administration of contrast agents during PCI or CAG could increase the resistance of renal vascular representing sustained vasoconstriction and decrease renal blood flow. The accumulation of contrast agents could create an osmotic environment that induces cellular apoptosis ${ }^{[34]}$. In the condition of overpressure and volume expansion, BNP is released from the membrane granules of cardiomyocytes. The contrast medium can be diluted and excreted by the effect of BNP in increasing diuresis and natriuresis. BNP also could increases GFR by dilating glomerular afferent arteries and constricting the efferent arteries. Nicorandil as prostaglandin analogues increases the renal blood flow by improving the release of nitric oxide and alleviates the inflammatory reaction by antagonizing the production of intracellular oxygen free radicals. The results of our study proved BNP and double-dose nicorandil could prevent the incidence of CIN. Although there is a difference in the mechanism of reducing the CIN between BNP and nicorandil, they all perform an important role in improving renal ischemia. Besides, BNP can aggravates the excretion of contrast agents and nicorandil presents 
271

272

273

274

275

276

277

278

279

280

281

282

283

284

285

286

287

288

289

290

291

292

293

294

295

296

297

relief of inflammatory reaction. Although this NMA demonstrated double-dose nicorandil presents better action than BNP, we considered it attributes to the reason for increasing dose. Therefore, we supported BNP is more suitable to prevent CIN incidence than nicorandil for consideration of adverse drug reactions.

Our results presented a statistically significant reduction of the occurrence of CIN and the change of SCr levels by pharmacological intervention from RCTs. The previous meta-analysis made by Xuebiao Wei et al ${ }^{[35]}$ summarized the incidence of CIN after intervention with BNP from five RCTs with 1441 patients but limited to study the SCr level change. Past meta-analysis lack a comparison study in treatment effect and intervention dose between BNP and nicorandil for preventing CIN incidence. Compared with these previous reports, there are several advantages to consider in our analysis. First, our study compared the intervention efficacy of BNP and nicorandil for CIN prevention and analyzed the SCr levels change which the previous study hasn't researched. Second, we made a dose-effect relationship and treatment course comparison for nicorandil. It's important for using pharmacological intervention during the PCI or CAG by appropriate dosage and course in clinical practice application. In a previous study, the efficacy comparison of different dose drugs and different treatment courses on reducing the incidence of CIN and the change of SCr levels hasn't been considered. In this work, in the process of analyzing the RCTs of nicorandil, we found the treatment course of nicorandil is different among trails. Based on the efficacy of double-dose nicorandil in preventing CIN, we analyzed whether the treatment course influent the efficacy of double-dose nicorandil. We divided into two different kinds of the treatment course of double-dose nicorandil. One course is less than or equal to $24 \mathrm{~h}$ before and after the procedure, the other course is 4-5 days before and after the procedure. To our surprise, the shorter the course of treatment, the better the treatment effect in decreasing CIN and SCr levels. It recommended when nicorandil was applied to prevent CIN, 30mg daily of nicorandil should be administrated from 12 $\mathrm{h}$ before to $12 \mathrm{~h}$ after the procedure. However, there are some limitations to this study. First, a small number of trials with insufficient participants may affect the accuracy of evaluating the treatment effect. Second, the time of diagnosing the CIN after PCI and CAG varied among studies. 
Therefore, we analyzed one outcome of CIN incidence by odds ratio according to the result of the included study report. Third, the relationship between CIN and clinical consequences wasn't investigated because of insufficient data.

5. Conclusion

This study is the first network meta-analysis to compare the efficacy of BNP, nicorandil, nitroglycerine, and intravenous saline in preventing the occurrence of CIN. Compared with intravenous saline alone, combined with BNP or double-dose nicorandil (30mg) could prevent CIN incidence in PCI and CAG. Based on direct and indirect comparison, SUCRA ranking indicates $30 \mathrm{mg}$ daily nicorandil performs better efficacy than BNP $(1.5 \mathrm{ug} / \mathrm{kg})$ for $24 \mathrm{~h}$ in reducing the SCr levels and CIN incidence. The best course of 30mg nicorandil is from $12 \mathrm{~h}$ before to $12 \mathrm{~h}$ after the procedure.

\section{Compliance with ethical standards}

\section{Conflict of interest None.}

\section{Reference}

[1] Rear R, Bell RM, Hausenloy DJ. Contrast-induced nephropathy following angiography and cardiac interventions. Heart. 2016 Apr;102(8):638-48. DOI: 10.1136/heartjnl-2014-306962. Epub 2016 Feb 8. PMID: 26857214; PMCID: PMC4819627.

[2] Owen RJ, Hiremath S, Myers A, Fraser-Hill M, Barrett BJ. Canadian Association of Radiologists consensus guidelines for the prevention of contrast-induced nephropathy: update 2012. Can Assoc Radiol J. 2014 May;65(2):96-105. DOI: 10.1016/j.carj.2012.11.002. Epub 2014 Feb 20. PMID: 24559602.

[3] Grossman PM, Ali SS, Aronow HD, Boros M, Nypaver TJ, Schreiber TL, Park YJ, Henke PK, Gurm HS. Contrast-induced nephropathy in patients undergoing endovascular peripheral vascular intervention: Incidence, risk factors, and outcomes as observed in the Blue Cross Blue Shield of Michigan Cardiovascular Consortium. J Interv Cardiol. 2017 Jun;30(3):274280. DOI: 10.1111/joic.12379. Epub 2017 Apr 3. PMID: 28370487.

[4] Tepel M, Aspelin P, Lameire N. Contrast-induced nephropathy: a clinical and evidence-based approach. Circulation. $2006 \quad$ Apr $11 ; 113(14): 1799-806 . \quad$ DOI: 10.1161/CIRCULATIONAHA.105.595090. PMID: 16606801.

[5] Chyou AC, Thodge A, Feldman DN, Swaminathan RV. Statins in the prevention of contrastinduced nephropathy. Curr Treat Options Cardiovasc Med. 2015 Apr;17(4):375. DOI: 10.1007/s11936-015-0375-0. PMID: 25778426. 
332

333

334

335

336

337

338

339

340

341

342

343

344

345

346

347

348

349

350

351

352

353

354

355

356

357

358

359

360

361

362

363

364

365

366

367

368

369

370

371

372

[6] Ali-Hasan-Al-Saegh S, Mirhosseini SJ, Ghodratipour Z, Sarrafan-Chaharsoughi Z, Rahimizadeh E, Karimi-Bondarabadi AA, Haddad F, Shahidzadeh A, Mahdavi P, Dehghan AM, Tahernejad M, Shahidzadeh A, Dehghan H, Ghanei A, Lotfaliani M, Weymann A, Zeriouh M, Popov AF, Sabashnikov A. Strategies Preventing Contrast-Induced Nephropathy After Coronary Angiography: A Comprehensive Meta-Analysis and Systematic Review of 125 Randomized Controlled Trials. Angiology. 2017 May;68(5):389-413. DOI: 10.1177/0003319716661445. Epub 2016 Aug 1. PMID: 27485363.

[7] Uzunhasan I, Yildiz A, Arslan S, Abaci O, Kocas C, Kocas BB, Cetinkal G, Dalgic Y, Karaca OS, Dogan SM. Contrast-Induced Acute Kidney Injury Is Associated With Long-Term Adverse Events in Patients With Acute Coronary syndrome. Angiology. 2017 Aug;68(7):621626. DOI: 10.1177/0003319716676173. Epub 2016 Nov 12. PMID: 28660805.

[8] Grossman PM, Ali SS, Aronow HD, Boros M, Nypaver TJ, Schreiber TL, Park YJ, Henke PK, Gurm HS. Contrast-induced nephropathy in patients undergoing endovascular peripheral vascular intervention: Incidence, risk factors, and outcomes as observed in the Blue Cross Blue Shield of Michigan Cardiovascular Consortium. J Interv Cardiol. 2017 Jun;30(3):274280. DOI: 10.1111/joic.12379. Epub 2017 Apr 3. PMID: 28370487.

[9] Subramaniam RM, Suarez-Cuervo C, Wilson RF, Turban S, Zhang A, Sherrod C, Aboagye J, Eng J, Choi MJ, Hutfless S, Bass EB. Effectiveness of Prevention Strategies for ContrastInduced Nephropathy: A Systematic Review and Meta-analysis. Ann Intern Med. 2016 Mar 15;164(6):406-16. DOI: 10.7326/M15-1456. Epub 2016 Feb 2. PMID: 26830221.

[10]Marenzi G, Cosentino N, Werba JP, Tedesco CC, Veglia F, Bartorelli AL. A meta-analysis of randomized controlled trials on statins for the prevention of contrast-induced acute kidney injury in patients with and without acute coronary syndromes. Int J Cardiol. 2015 Mar 15;183:47-53. DOI: 10.1016/j.ijcard.2015.01.046. Epub 2015 Jan 29. PMID: 25662053.

[11]Wei XB, Jiang L, Liu XR, Yu DQ, Tan N, Chen JY, Zhou YL, He PC, Liu YH. Brain natriuretic peptide for prevention of contrast-induced nephropathy: a meta-analysis of randomized controlled trials. Eur J Clin Pharmacol. 2016 Nov;72(11):1311-1318. DOI: 10.1007/s00228-016-2135-9. Epub 2016 Oct 1. PMID: 27695914.

[12]Pranata R, Vania R, Alkatiri AA, Firman D, Lukito AA. Nicorandil Reduces the Incidence of Contrast-Induced Nephropathy in Patients Undergoing Coronary Angiography/Intervention Systematic Review and Meta-Analysis of Randomized Controlled Trials Including GRADE Qualification. Cardiovasc Revasc Med. 2020 Sep;21(9):1121-1127. DOI: 10.1016/j.carrev.2020.01.010. Epub 2020 Jan 13. PMID: 31959562.

[13]Fan Y, Wei Q, Cai J, Shi Y, Zhang Y, Yao L, Wang X, Lin S, Li Y, Lv J, Zhou B, Du R. Preventive effect of oral nicorandil on contrast-induced nephropathy in patients with renal insufficiency undergoing elective cardiac catheterization. Heart Vessels. 2016 Nov;31(11):1776-1782. DOI: 10.1007/s00380-016-0809-y. Epub 2016 Feb 13. PMID: 26874946.

[14]Xing K, Fu X, Wang Y, Li W, Gu X, Hao G, Miao Q, Li S, Jiang Y, Fan W, Geng W. Effect of rhBNP on renal function in STEMI-HF patients with mild renal insufficiency undergoing primary PCI. Heart Vessels. 2016 Apr;31(4):490-8. DOI: 10.1007/s00380-015-0642-8. Epub 
2015 Jan 31. PMID: 25637044.

[15]Zeng Z, Fu X, Zhang X, Fu N. Comparison of double-dose vs. usual dose of nicorandil for the prevention of contrast-induced nephropathy after cardiac catheterization. Int Urol Nephrol. 2019 Nov;51(11):1999-2004. DOI: 10.1007/s11255-019-02244-9. Epub 2019 Aug 5. PMID: 31385178.

[16]Zhang J, Fu X, Jia X, Fan X, Gu X, Li S, Wu W, Fan W, Su J, Hao G, Jiang Y, Xue L. B-type natriuretic peptide for prevention of contrast-induced nephropathy in patients with heart failure undergoing primary percutaneous coronary intervention. Acta Radiol. 2010 Jul;51(6):641-8. DOI: 10.3109/02841851.2010.486804. PMID: 20438292.

[17]Zhang X, Yang S, Zhang P, Fu N. Efficacy of nicorandil on the prevention of contrast-induced nephropathy in patients with coronary heart disease undergoing percutaneous coronary intervention. Coron Artery Dis. 2020 May;31(3):284-288. DOI: 10.1097/MCA.0000000000000826. PMID: 31658134.

[18]Fan Z, Li Y, Ji H, Jian X. Efficacy of Oral Nicorandil to Prevent Contrast-Induced Nephropathy in Patients with Chronic Renal Dysfunction Undergoing an Elective Coronary Procedure. Kidney Blood Press Res. 2019;44(6):1372-1382. DOI: 10.1159/000503160. Epub 2019 Oct 22. PMID: 31639790.

[19]Iranirad L, Hejazi SF, Sadeghi MS, Jang SA. Efficacy of nicorandil treatment for prevention of contrast-induced nephropathy in high-risk patients undergoing cardiac catheterization: A prospective randomized controlled trial. Cardiol J. 2017;24(5):502-507. DOI: 10.5603/CJ.a2017.0028. Epub 2017 Mar 10. PMID: 28281738.

[20]Ko YG, Lee BK, Kang WC, Moon JY, Cho YH, Choi SH, Hong MK, Jang Y, Kim JY, Min PK, Kwon HM; PRINCIPLE Investigators. Preventive effect of pretreatment with intravenous nicorandil on contrast-induced nephropathy in patients with renal dysfunction undergoing coronary angiography (PRINCIPLE Study). Yonsei Med J. 2013 Jul;54(4):957-64. DOI: 10.3349/ymj.2013.54.4.957. PMID: 23709432; PMCID: PMC3663233.

[21]Liu JM, Xie YN, Gao ZH, Zu XG, Li YJ, Hao YM, Chang L. Brain natriuretic peptide for prevention of contrast-induced nephropathy after percutaneous coronary intervention or coronary angiography. Can J Cardiol. 2014 Dec;30(12):1607-12. DOI: 10.1016/j.cjca.2014.08.012. Epub 2014 Aug 23. PMID: 25418218.

[22]Liu J, Xie Y, He F, Gao Z, Hao Y, Zu X, Chang L, Li Y. Recombinant Brain Natriuretic Peptide for the Prevention of Contrast-Induced Nephropathy in Patients with Chronic Kidney Disease Undergoing Nonemergent Percutaneous Coronary Intervention or Coronary Angiography: A Randomized Controlled Trial. Biomed Res Int. 2016;2016:5985327. DOI: 10.1155/2016/5985327. Epub 2016 Feb 2. PMID: 26949703; PMCID: PMC4754465.

[23]Zhang P, Li WY, Yang SC, Fu NK, Liu XG, Zhang X, Cong HL, Lin WH, Tian FS, Lu CZ, Zhang J. Preventive Effects of Nicorandil Against Contrast-Induced Nephropathy in Patients With Moderate Renal Insufficiency Undergoing Percutaneous Coronary Intervention. Angiology. 2020 Feb;71(2):183-188. DOI: 10.1177/0003319719841733. Epub 2019 Apr 15. PMID: 30987432.

[24]Nawa T, Nishigaki K, Kimura Y, Tanaka T, Yamada Y, Kawasaki M, Minatoguchi S. 
Continuous intravenous infusion of nicorandil for 4 hours before and 24 hours after percutaneous coronary intervention protects against contrast-induced nephropathy in patients with poor renal function. Int $J$ Cardiol. 2015 Sep 15;195:228-34. DOI: 10.1016/j.ijcard.2015.05.078. Epub 2015 May 22. PMID: 26048382.

[25] Sun C, Zhi J, Bai X, Li X, Xia H. Comparison of the efficacy of recombinant human brain natriuretic peptide with saline hydration in preventing contrast-induced nephropathy in patients undergoing coronary angiography with or without concomitant percutaneous coronary intervention. Int J Clin Exp Med. 2015 Aug 15;8(8):14166-72. PMID: 26550389; PMCID: PMC4613074.

[26]Zhang F, Lu Z, Wang F. Advances in the pathogenesis and prevention of contrast-induced nephropathy. Life Sci. 2020 Oct 15;259:118379. DOI: 10.1016/j.lfs.2020.118379. Epub 2020 Sep 3. PMID: 32890604.

[27]Nijssen EC, Nelemans PJ, Rennenberg RJ, Theunissen RA, van Ommen V, Wildberger JE. Prophylaxis in High-Risk Patients With eGFR $<30 \mathrm{~mL} / \mathrm{min} / 1.73 \mathrm{~m} 2$ : Get the Balance Right. Invest Radiol. 2019 Sep;54(9):580-588. doi: 10.1097/RLI.0000000000000570. PMID: 31033672 .

[28]Nijssen EC, Nelemans PJ, Rennenberg RJ, van der Molen AJ, van Ommen GV, Wildberger JE. Impact on clinical practice of updated guidelines on iodinated contrast material: CINART. Eur Radiol. 2020 Jul;30(7):4005-4013. doi: 10.1007/s00330-020-06719-7. Epub 2020 Feb 27. PMID: 32107605; PMCID: PMC7305084.

[29]Potter LR, Yoder AR, Flora DR, Antos LK, Dickey DM. Natriuretic peptides: their structures, receptors, physiologic functions, and therapeutic applications. Handb Exp Pharmacol. 2009;(191):341-66. DOI: 10.1007/978-3-540-68964-5_15. PMID: 19089336; PMCID: PMC4855512.

[30]Holmes SJ, Espiner EA, Richards AM, Yandle TG, Frampton C. Renal, endocrine, and hemodynamic effects of human brain natriuretic peptide in normal man. J Clin Endocrinol Metab. 1993 Jan;76(1):91-6. DOI: 10.1210/jcem.76.1.8380606. PMID: 8380606.

[31] Shimizu S, Saito M, Kinoshita Y, Ohmasa F, Dimitriadis F, Shomori K, Hayashi A, Satoh K. Nicorandil ameliorates ischemia-reperfusion injury in the rat kidney. Br J Pharmacol. 2011 May;163(2):272-82. DOI: 10.1111/j.1476-5381.2011.01231.x. PMID: 21250976; PMCID: PMC3087131.

[32]Fan Y, Wei Q, Cai J, Shi Y, Zhang Y, Yao L, Wang X, Lin S, Li Y, Lv J, Zhou B, Du R. Preventive effect of oral nicorandil on contrast-induced nephropathy in patients with renal insufficiency undergoing elective cardiac catheterization. Heart Vessels. 2016 Nov;31(11):1776-1782. DOI: 10.1007/s00380-016-0809-y. Epub 2016 Feb 13. PMID: 26874946.

[33]Dugbartey GJ, Redington AN. Prevention of contrast-induced nephropathy by limb isc hemic preconditioning: underlying mechanisms and clinical effects. Am J Physiol Ren al Physiol. 2018 Mar 1;314(3): F319-F328. DOI: 10.1152/ajprenal.00130.2017. Epub 2 017 May 31. PMID: 28566501.

[34]McCullough PA, Choi JP, Feghali GA, Schussler JM, Stoler RM, Vallabahn RC, Mehta A. 
455 Contrast-Induced Acute Kidney Injury. J Am Coll Cardiol. 2016 Sep 27;68(13):1465-1473.

456 DOI: 10.1016/j.jacc.2016.05.099. PMID: 27659469.

457 [35] Wei XB, Jiang L, Liu XR, Yu DQ, Tan N, Chen JY, Zhou YL, He PC, Liu YH. Brain natriuretic peptide for prevention of contrast-induced nephropathy: a meta-analysis of randomized controlled trials. Eur J Clin Pharmacol. 2016 Nov;72(11):1311-1318. DOI: 10.1007/s00228-016-2135-9. Epub 2016 Oct 1. PMID: 27695914.

461

462 


\section{Figure 1}

Flow diagram of literature search and selection.

The flow diagram was depicted following the guideline of Preferred Reporting Items for Systematic Reviews and Meta-Analyses (PRISMA). 


\section{PRISMA 2009 Flow Diagram}
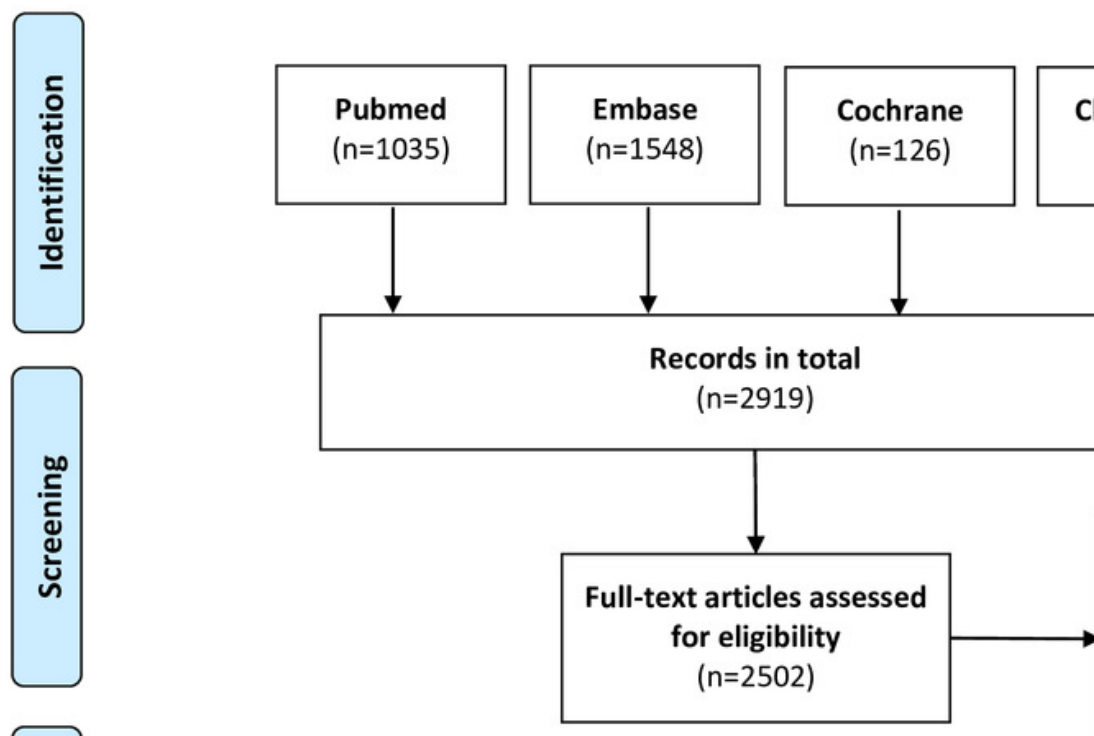

Records excluded $(n=2474)$

Case report $(n=122)$

Review $(n=417)$

Conference paper $(n=249)$

Irrelevant article $(n=1686)$
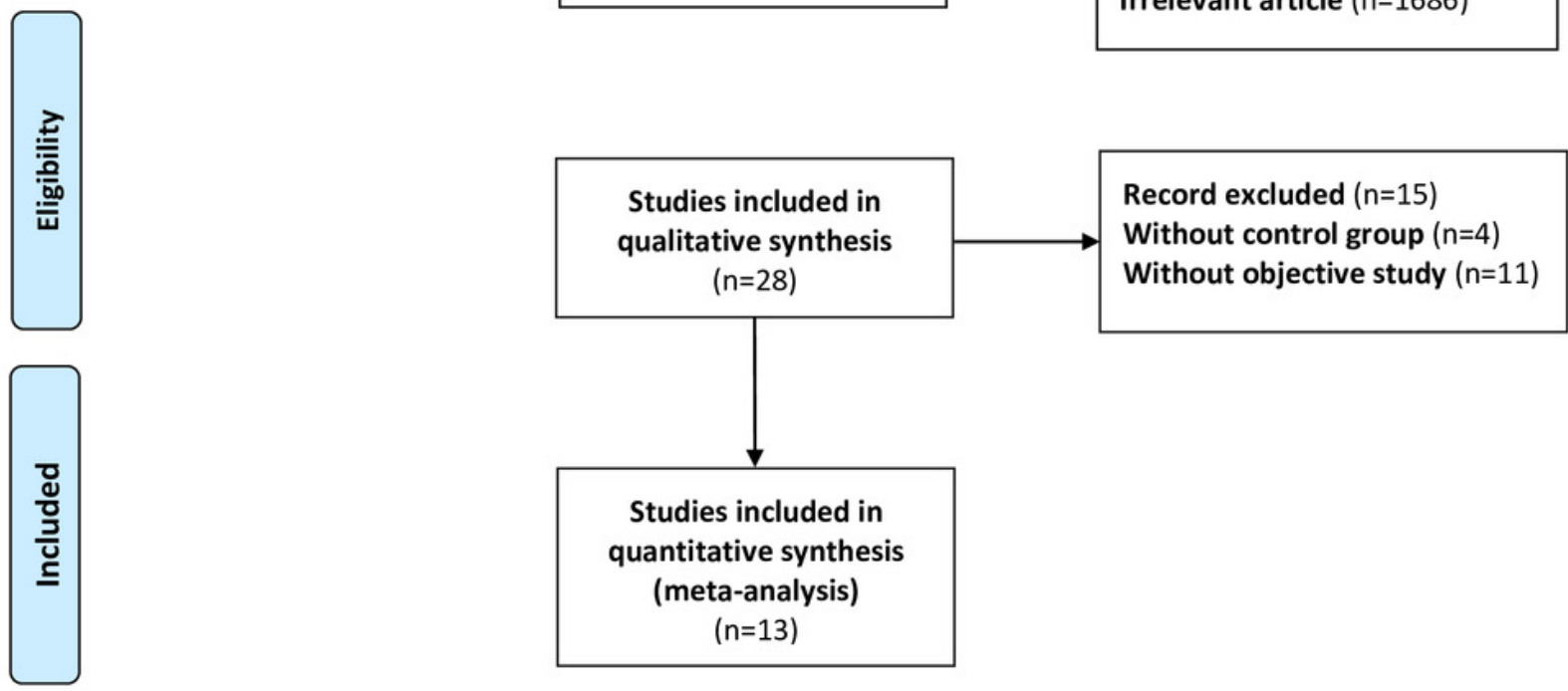

From: Moher D, Liberati A, Tetzlaff J, Altman DG, The PRISMA Group (2009). Preferred Reporting Atems for Systematic Reviews and MetaAnalyses: The PRISMA Statement. PLoS Med 6(7): e1000097. doi:10.1371/journal.pmed1000097

For more information, visit www.prisma-statement.org. 
Figure 2

Network of all the drugs included in the analysis

(A) Network of all included agents for decreasing the occurrence of CIN. (B) Network of all included agents for the efficacy of reducing the change of $\mathrm{SCr}$ levels. Nodes present the comparison among treatments. The width of the lines and the number of trials comparing each pair of drug agents were in the direct ratio. The size of the node is proportional to the number of participants and presents the sample size. BNP, brain natriuretic peptide.

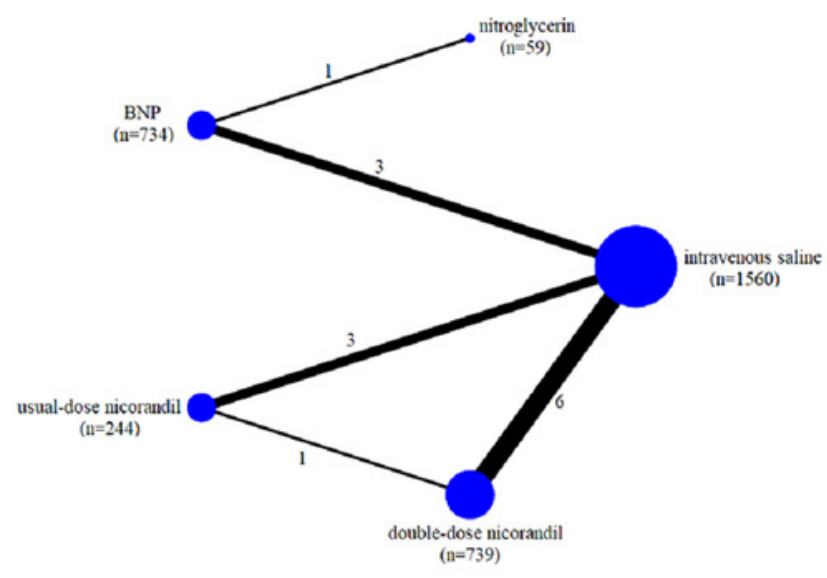

A

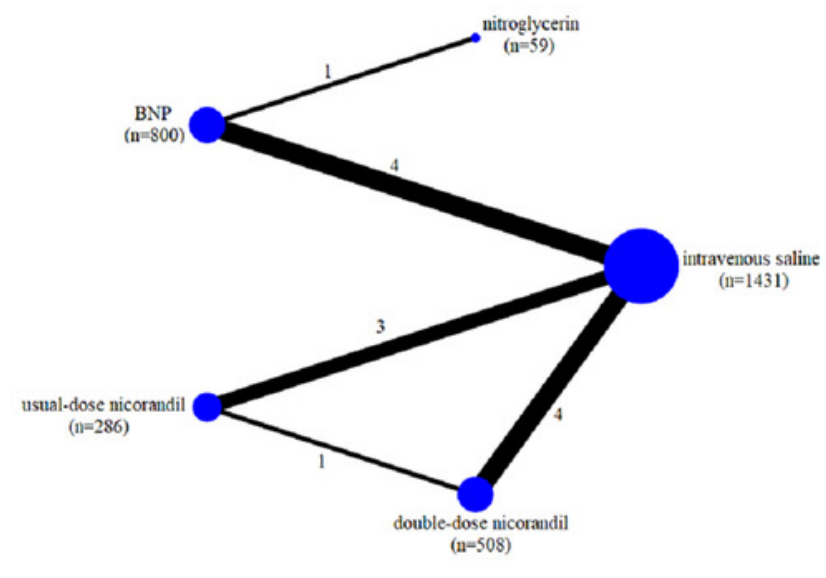

B 


\section{Table $\mathbf{1}$ (on next page)}

Characteristics of included studies in the network meta-analysis

BUN: Blood urea nitrogen; Scr: Serum creatinine; eGFR: Estimated glomerular filtration rate; CIN: Contrast-induced nephropathy; Cys-C: Cystatin C; RCT: randomized controlled trial; SD: standard deviation ; BNP: brain natriuretic peptide. 
Table 1 Characteristics of include studies in the network meta-analysis

\begin{tabular}{|c|c|c|c|c|c|c|c|c|c|}
\hline Author /year & Size & Follow-up & Age & Study type & Interventions (no.) & Comparisons & Outcomes & Measures & Risk of bias \\
\hline Liu/2014 & 1000 & 7days & $67 y$ & $\mathrm{RCT}$ & $\begin{array}{l}0.9 \% \mathrm{NaCl}(1 \mathrm{~mL} / \mathrm{kg} / \mathrm{h})(\mathrm{n}=500) \\
\mathrm{BNP}(0.005 \mathrm{ug} / \mathrm{kg} / \mathrm{min})(\mathrm{n}=500)\end{array}$ & BNP vs $0.9 \% \mathrm{NaCl}$ & $\begin{array}{l}\text { BUN, Scr, eGFR, } \\
\text { CIN occurrence }\end{array}$ & $\begin{array}{l}\text { odds ratio } \\
\text { Mean+SD }\end{array}$ & low risk \\
\hline Liu/2015 & 209 & 1 month & $69 y$ & $\mathrm{RCT}$ & $\begin{array}{l}0.9 \% \mathrm{NaCl}(1 \mathrm{~mL} / \mathrm{kg} / \mathrm{h})(\mathrm{n}=103) \\
\mathrm{BNP}(0.005 \mathrm{ug} / \mathrm{kg} / \mathrm{min})(\mathrm{n}=106)\end{array}$ & BNP vs $0.9 \% \mathrm{NaCl}$ & $\begin{array}{l}\text { Scr, eGFR, CIN } \\
\text { occurrence }\end{array}$ & $\begin{array}{l}\text { odds ratio } \\
\text { Mean } \pm \text { SD }\end{array}$ & low risk \\
\hline Sun/2015 & 126 & $72 \mathrm{~h}$ & $60 y$ & $\mathrm{RCT}$ & $\begin{array}{l}0.9 \% \mathrm{NaCl}(1 \mathrm{~mL} / \mathrm{kg} / \mathrm{h})(\mathrm{n}=63) \\
\mathrm{BNP}(1.5 \mathrm{ug} / \mathrm{kg})(\mathrm{n}=63)\end{array}$ & BNP vs $0.9 \% \mathrm{NaCl}$ & $\begin{array}{l}\text { Scr, } \quad \mathrm{CCl}, \quad \mathrm{CIN} \\
\text { occurrence }\end{array}$ & $\begin{array}{l}\text { odds ratio } \\
\text { Mean+SD }\end{array}$ & low risk \\
\hline Xing/2015 & 116 & $72 \mathrm{~h}$ & $64 y$ & $\mathrm{RCT}$ & $\begin{array}{l}\text { nitroglycerin }(20 \mathrm{ug} / \mathrm{min})(\mathrm{n}=59) \\
\operatorname{BNP}(1.5 \mathrm{ug} / \mathrm{kg})(\mathrm{n}=57)\end{array}$ & BNP vs nitroglycerin & $\begin{array}{l}\text { Scr, eGFR, Cys-C, } \\
\text { CIN occurrence }\end{array}$ & $\begin{array}{l}\text { odds ratio } \\
\text { Mean+SD }\end{array}$ & low risk \\
\hline Zhang/2010 & 149 & 7 days & $65 y$ & $\mathrm{RCT}$ & $\begin{array}{l}0.9 \% \mathrm{NaCl}(0.5-1.5 \mathrm{~mL} / \mathrm{kg})(\mathrm{n}=75) \\
\mathrm{BNP}(1.5 \mathrm{ug} / \mathrm{kg})(\mathrm{n}=74)\end{array}$ & BNP vs $0.9 \% \mathrm{NaCl}$ & $\begin{array}{l}\text { Scr, eGFR, CIN } \\
\text { occurrence }\end{array}$ & $\begin{array}{l}\text { odds ratio } \\
\text { Mean_SD }\end{array}$ & low risk \\
\hline Fan/2016 & 240 & $72 \mathrm{~h}$ & $67 y$ & $\mathrm{RCT}$ & $\begin{array}{l}0.9 \% \mathrm{NaCl}(1 \mathrm{~mL} / \mathrm{kg} / \mathrm{h})(\mathrm{n}=120) \\
\text { nicorandil }(30 \mathrm{mg})(\mathrm{n}=120)\end{array}$ & $\begin{array}{l}\text { double-dose nicorandil vs } \\
0.9 \% \mathrm{NaCl}\end{array}$ & $\begin{array}{l}\text { Scr, eGFR, Cys-C, } \\
\text { CIN occurrence }\end{array}$ & $\begin{array}{l}\text { odds ratio } \\
\text { Mean+SD }\end{array}$ & low risk \\
\hline Fan/2019 & 252 & $72 \mathrm{~h}$ & $63 y$ & RCT & $\begin{array}{l}0.9 \% \mathrm{NaCl}(1 \mathrm{~mL} / \mathrm{kg} / \mathrm{h})(\mathrm{n}=125) \\
\text { nicorandil }(30 \mathrm{mg})(\mathrm{n}=127)\end{array}$ & $\begin{array}{l}\text { double-dose nicorandil vs } \\
0.9 \% \mathrm{NaCl}\end{array}$ & $\begin{array}{l}\text { Scr, eGFR, Cys-C, } \\
\text { CIN occurrence }\end{array}$ & $\begin{array}{l}\text { odds ratio } \\
\text { Mean+SD }\end{array}$ & low risk \\
\hline Iranirad/2017 & 128 & $72 \mathrm{~h}$ & $61 \mathrm{y}$ & $\mathrm{RCT}$ & $\begin{array}{l}0.9 \% \mathrm{NaCl}(1 \mathrm{~mL} / \mathrm{kg} / \mathrm{h})(\mathrm{n}=64) \\
\text { nicorandil }(10 \mathrm{mg})(\mathrm{n}=64)\end{array}$ & $\begin{array}{l}\text { usual-dose nicorandil vs } \\
0.9 \% \mathrm{NaCl}\end{array}$ & $\begin{array}{l}\text { Scr, eGFR, CIN } \\
\text { occurrence }\end{array}$ & $\begin{array}{l}\text { odds ratio } \\
\text { Mean } \pm \text { SD }\end{array}$ & low risk \\
\hline $\begin{array}{l}\text { Ko/2013 } \\
\text { NCT01103336 }\end{array}$ & 166 & $48 \mathrm{~h}$ & $71 y$ & $\mathrm{RCT}$ & $\begin{array}{l}0.9 \% \operatorname{NaCl}(100 \mathrm{~mL})(\mathrm{n}=85) \\
\text { nicorandil }(12 \mathrm{mg})(\mathrm{n}=81)\end{array}$ & $\begin{array}{l}\text { usual-dose nicorandil vs } \\
0.9 \% \mathrm{NaCl}\end{array}$ & $\begin{array}{l}\text { Scr, eGFR, CIN } \\
\text { occurrence }\end{array}$ & $\begin{array}{l}\text { odds ratio } \\
\text { Mean+SD }\end{array}$ & low risk \\
\hline $\begin{array}{l}\text { Nawa/2015 } \\
\text { UMIN000008544 }\end{array}$ & 213 & 1 month & $70 y$ & $\mathrm{RCT}$ & $\begin{array}{l}0.9 \% \mathrm{NaCl}(1.1 \mathrm{~mL} / \mathrm{kg} / \mathrm{h})(\mathrm{n}=107) \\
\text { nicorandil }(48 \mathrm{mg})(\mathrm{n}=106)\end{array}$ & $\begin{array}{l}\text { double-dose nicorandil vs } \\
0.9 \% \mathrm{NaCl}\end{array}$ & $\begin{array}{l}\text { Scr, eGFR, Cys-C, } \\
\text { CIN occurrence }\end{array}$ & $\begin{array}{l}\text { odds ratio } \\
\text { Mean } \pm \text { SD }\end{array}$ & low risk \\
\hline Zeng/2019 & 330 & $48 \mathrm{~h}$ & $66 y$ & $\mathrm{RCT}$ & $\begin{array}{l}0.9 \% \mathrm{NaCl}(1.1 \mathrm{~mL} / \mathrm{kg} / \mathrm{h})(\mathrm{n}=112) \\
\text { usual-dose nicorandil }(15 \mathrm{mg})(\mathrm{n}=107) \\
\text { double-dose nicorandil }(30 \mathrm{mg})(\mathrm{n}=111)\end{array}$ & $\begin{array}{l}\text { usual-dose nicorandil vs } \\
0.9 \% \mathrm{NaCl} \\
\text { double-dose nicorandil vs } \\
0.9 \% \mathrm{NaCl}\end{array}$ & $\begin{array}{l}\text { BUN, Scr, eGFR, } \\
\text { Cys-C,CIN } \\
\text { occurrence }\end{array}$ & $\begin{array}{l}\text { odds ratio } \\
\text { Mean } \pm \text { SD }\end{array}$ & low risk \\
\hline Zhang, MD/2019 & 250 & $72 \mathrm{~h}$ & $67 y$ & $\mathrm{RCT}$ & $\begin{array}{l}0.9 \% \mathrm{NaCl}(1.0 \mathrm{~mL} / \mathrm{kg} / \mathrm{h})(\mathrm{n}=125) \\
\text { nicorandil }(30 \mathrm{mg})(\mathrm{n}=125)\end{array}$ & $\begin{array}{l}\text { double-dose nicorandil vs } \\
0.9 \% \mathrm{NaCl}\end{array}$ & $\begin{array}{l}\text { BUN, Scr, } \mathrm{crCl} \\
\text { CIN occurrence }\end{array}$ & $\begin{array}{l}\text { odds ratio } \\
\text { Mean+SD }\end{array}$ & low risk \\
\hline
\end{tabular}


Zhang/2019

BUN: Blood urea nitrogen; Scr: Serum creatinine; eGFR: Estimated glomerular filtration rate; CIN: Contrast-induced nephropathy; Cys-C: Cystatin

C; RCT: randomized controlled trial; SD: standard deviation; BNP: brain natriuretic peptide. 
Figure 3

Forest plots of network meta-analysis

(A) Forest plots of network meta-analysis of all trials for decreasing the occurrence of CIN. (B)

Forest plots of network meta-analysis of all trials for the efficacy of reducing the change of

SCr levels. $a=$ =intravenous saline; $b=$ nitroglycerin; $c=B N P ; d=$ usual-dose nicorandil;

$\mathrm{e}=$ double-dose nicorandil. OR, odds ratios.

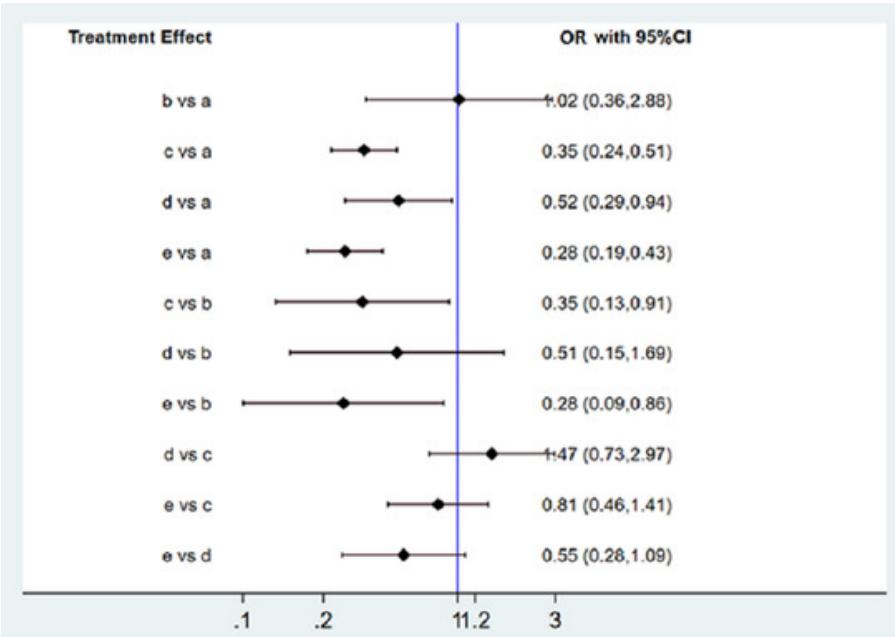

$\mathbf{A}$

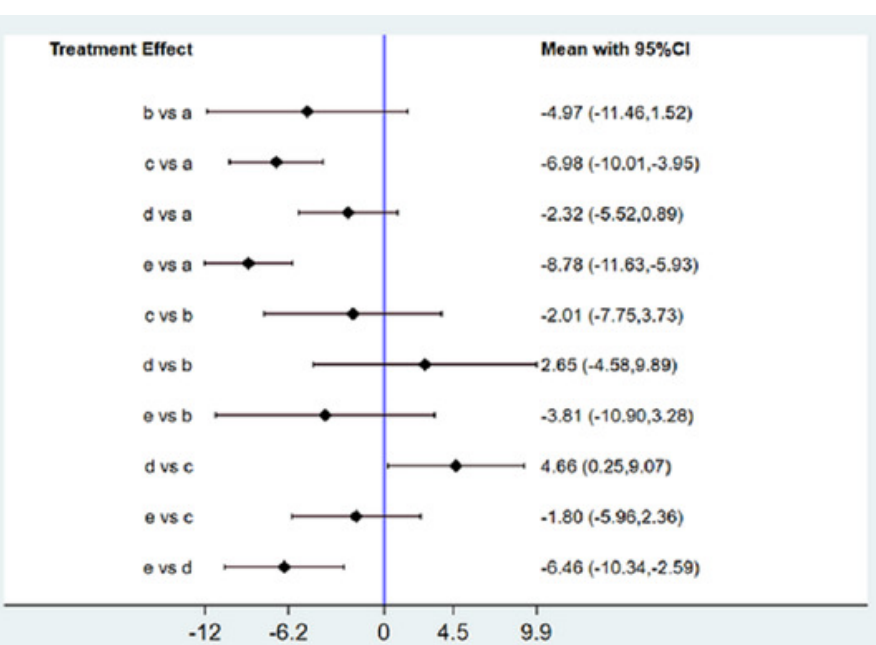

B 


\section{Table 2 (on next page)}

Baseline characteristics of studies included population

BNP: brain natriuretic peptide ; SD: standard deviation ; LVEF: left ventricular ejection fraction; ACEl: angiotensin-converting enzyme inhibitors; ARB: angiotensin receptor blocker; CCB: calcium channel blockers; CAG: coronary angiography; $\mathrm{PCl}$ : percutaneous coronary intervention. 
Table 2 Baseline characteristics of studies included population

\begin{tabular}{|c|c|c|c|c|c|c|c|c|c|c|}
\hline Author /year & $\mathrm{Liu} / 2014$ & & Liu/2015 & & Sun/2015 & & Xing/2015 & & Zhang/2010 & \\
\hline Characteristic & $0.9 \% \mathrm{NaCl}$ & $\mathrm{BNP}$ & $0.9 \% \mathrm{NaCl}$ & $\mathrm{BNP}$ & $0.9 \% \mathrm{NaCl}$ & $\mathrm{BNP}$ & nitroglycerin & BNP & $0.9 \% \mathrm{NaCl}$ & BNP \\
\hline Number & 500 & 500 & 103 & 106 & 63 & 63 & 59 & 57 & 75 & 74 \\
\hline Age- years \pm SD & $65 \pm 8.7$ & $68 \pm 9.2$ & $69.8 \pm 6.7$ & $67.6 \pm 7.2$ & $60.37 \pm 9.26$ & $59.35 \pm 9.01$ & $58.64 \pm 11.51$ & $58.91 \pm 9.81$ & $67.27 \pm 7.07$ & $65.39 \pm 7.51$ \\
\hline Male (\%) & $337(67.4)$ & $347(69.2)$ & $63(61.2 \%)$ & $70(66.0 \%)$ & $39(61.9)$ & $38(60.3)$ & $40(67.80)$ & $41(71.93)$ & $53(67.7)$ & $52(73.4)$ \\
\hline Body mass index & $25.2+5.2$ & $23.7 \pm 4.5$ & $25.4 \pm 4.2$ & $24.9 \pm 5$ & $24.1 \pm 3.4$ & $23.8 \pm 3.7$ & $26.78 \pm 3.77$ & $27.16 \pm 4.42$ & $\mathrm{NA}$ & NA \\
\hline Diabetes mellitus(n\%) & $244(48.8)$ & $256(51.2)$ & $71(68.9 \%)$ & $76(71.7 \%)$ & $18(28.6)$ & $13(20.6)$ & $15(25.42)$ & $18(31.58)$ & $18(24)$ & $24(32.4)$ \\
\hline Hypertension(n\%) & $276(55.2)$ & 293(58.6) & $59(57.3 \%)$ & $62(58.5 \%)$ & $41(65.1)$ & $38(60.3)$ & $35(59.32)$ & $31(54.39)$ & NA & NA \\
\hline LVEF (\%) & $51 \pm 4.4$ & $53+4.6$ & $58.4 \pm 10.5$ & $61.1 \pm 8.2$ & $61.51 \pm 2.97$ & $61.81 \pm 3.12$ & $47.43 \pm 7.20$ & $44.95 \pm 7.80$ & $39.67 \pm 4.76$ & $39.14 \pm 3.87$ \\
\hline \multicolumn{11}{|l|}{ Drugs } \\
\hline ACEI/ARB (\%) & NA & NA & NA & NA & $23(36.5)$ & $23(36.5)$ & $44(74.58 \%)$ & $39(68.42 \%)$ & $59(78.7)$ & $61(81.3)$ \\
\hline$\beta$-block (\%) & NA & NA & NA & NA & $49(77.8)$ & $44(69.8)$ & $43(72.88 \%)$ & $48(84.21 \%)$ & $17(22.7)$ & $21(28.4)$ \\
\hline Statin (\%) & 491(98.2) & $480(96)$ & $102(99 \%)$ & $103(97 \%)$ & NA & NA & $56(94.92 \%)$ & $56(98.25 \%)$ & $\mathrm{NA}$ & NA \\
\hline Clopidogrel (\%) & $500(100)$ & $500(100)$ & NA & NA & NA & NA & $48(81.36 \%)$ & $51(89.47 \%)$ & NA & NA \\
\hline $\mathrm{CCB}$ & NA & NA & NA & NA & $24(38.1)$ & $16(25.4)$ & $31(52.54 \%)$ & $23(40.35 \%)$ & $\mathrm{NA}$ & NA \\
\hline Aspirin, n (\%) & $500(100)$ & $500(100)$ & NA & NA & NA & NA & NA & NA & NA & NA \\
\hline CAG, n (\%) & $175(35)$ & $156(32.2)$ & $36(35 \%)$ & $33(31.1 \%)$ & NA & NA & $\mathrm{NA}$ & NA & NA & NA \\
\hline PCI, n (\%) & $325(65)$ & $344(68.8)$ & $67(65 \%)$ & $73(68.9 \%)$ & NA & NA & NA & NA & NA & NA \\
\hline
\end{tabular}

Table 2 Baseline characteristics of studies included population

\begin{tabular}{|c|c|c|c|c|c|}
\hline Author/year & Fan/2016 & Fan/2019 & Iranirad/2017 & $\mathrm{Ko} / 2013$ & Nawa/2015 \\
\hline
\end{tabular}




\begin{tabular}{|c|c|c|c|c|c|c|c|c|c|c|}
\hline Characteristic & $0.9 \% \mathrm{NaCl}$ & $\begin{array}{l}\text { double-dose } \\
\text { nicorandil }\end{array}$ & $0.9 \% \mathrm{NaCl}$ & $\begin{array}{l}\text { double-dose } \\
\text { nicorandil }\end{array}$ & $0.9 \% \mathrm{NaCl}$ & $\begin{array}{l}\text { usual-dose } \\
\text { nicorandil }\end{array}$ & $0.9 \% \mathrm{NaCl}$ & $\begin{array}{l}\text { usual-dose } \\
\text { nicorandil }\end{array}$ & $0.9 \% \mathrm{NaCl}$ & $\begin{array}{l}\text { double- } \\
\text { dose }\end{array}$ \\
\hline Number & 120 & 120 & 125 & 127 & 64 & 64 & 85 & 81 & 107 & 106 \\
\hline Age- years \pm SD & $67.37 \pm 6.33$ & $66.07 \pm 6.37$ & $65.87 \pm 17.62$ & $62.25 \pm 16.63$ & $57.64 \pm 12.42$ & $61.35 \pm 11.77$ & $69.1 \pm 10.3$ & $70.8 \pm 9.6$ & $70.1 \pm 8.1$ & $70.4 \pm 7.7$ \\
\hline Male (\%) & $95(79.17)$ & $88(73.33)$ & $67(53.60)$ & $76(59.84)$ & $40(62.5 \%)$ & $39(60.9 \%)$ & $51(67.1)$ & $53(72.6)$ & $74(78.7)$ & $80(81.6)$ \\
\hline Body mass index & $22.28 \pm 2.98$ & $22.36 \pm 2.19$ & $23.78 \pm 5.98$ & $24.35 \pm 5.87$ & $27.78 \pm 4.8$ & $28.43 \pm 5.6$ & $24.8 \pm 3.7$ & $24.1 \pm 3.2$ & $23.5 \pm 2.9$ & $23.4 \pm 3.4$ \\
\hline Diabetes mellitus(n\%) & $62(51.67)$ & $66(55.00)$ & $75(60)$ & $81(63.78)$ & $26(40.6 \%)$ & $27(42.2 \%)$ & $42(55.3)$ & $30(41.1)$ & NA & NA \\
\hline Hypertension(n\%) & $74(61.67)$ & $69(57.50)$ & $62(49.6)$ & $68(53.54)$ & $41(64.1 \%)$ & $35(54.7 \%)$ & $61(80.3)$ & $57(78.1)$ & NA & $\mathrm{NA}$ \\
\hline LVEF (\%) & $51.15 \pm 6.36$ & $50.36 \pm 5.29$ & $53.58 \pm 12.77$ & $51.39 \pm 10.35$ & $49.14 \pm 5.8$ & $48.87 \pm 6.8$ & NA & NA & NA & NA \\
\hline \multicolumn{11}{|l|}{ Drugs } \\
\hline ACEI/ARB (\%) & $47(39.17)$ & $56(46.67)$ & $44(35.20)$ & $46(36.22)$ & NA & NA & $43(56.6)$ & $47(64.4)$ & $10(10.6)$ & $4(4.1)$ \\
\hline$\beta$-block (\%) & $94(78.33)$ & $101(84.17)$ & $53(42.40)$ & $61(48.03)$ & NA & NA & $35(46.1)$ & $42(57.5)$ & $23(23.4)$ & $35(35.7)$ \\
\hline Clopidogrel (\%) & NA & NA & $79(63.20)$ & $83(65.35)$ & NA & NA & NA & NA & NA & NA \\
\hline $\mathrm{CCB}$ & $34(28.33)$ & $28(23.33)$ & $56(44.80)$ & $50(39.37)$ & NA & NA & $36(47.4)$ & $34(46.6)$ & NA & NA \\
\hline Aspirin, n (\%) & $\mathrm{NA}$ & $\mathrm{NA}$ & $101(80.80)$ & $108(85.04)$ & $\mathrm{NA}$ & NA & NA & $\mathrm{NA}$ & $\mathrm{NA}$ & $\mathrm{NA}$ \\
\hline CAG, n (\%) & $75(62.50)$ & $68(56.67)$ & NA & NA & NA & NA & NA & NA & NA & NA \\
\hline PCI, n (\%) & $27(22.50)$ & $31(25.83)$ & NA & NA & NA & NA & NA & NA & NA & NA \\
\hline
\end{tabular}


BNP: brain natriuretic peptide; SD: standard deviation; LVEF: left ventricular ejection fraction; ACEI: angiotension converting enzyme inhibitors;

ARB: angiotensin receptor blocker; CCB: calcium channel blockers; CAG: coronary angiography; PCI: percutaneous coronary intervention.

Table 2 Baseline characteristics of studies included population

\begin{tabular}{|c|c|c|c|c|c|c|c|}
\hline \multirow{2}{*}{$\begin{array}{l}\text { Author/year } \\
\text { Characteristic }\end{array}$} & \multicolumn{2}{|l|}{ Zhang/2019 } & \multicolumn{2}{|c|}{ MD, Zhang/2019 } & \multicolumn{3}{|l|}{ Zeng/2019 } \\
\hline & $0.9 \% \mathrm{NaCl}$ & double-dose nicorandil & $0.9 \% \mathrm{NaCl}$ & double-dose nicorandil & $0.9 \% \mathrm{NaCl}$ & usual-dose nicorandil & double-dose nicorandil \\
\hline Number & 125 & 125 & 150 & 150 & 1112 & 107 & 111 \\
\hline Age- years \pm SD & $67.11 \pm 7.19$ & $67.25 \pm 6.42$ & $67.0 \pm 7.2$ & $67.4 \pm 6.6$ & $66.69 \pm 7.33$ & $67.09 \pm 6.85$ & $65.37 \pm 7.19$ \\
\hline Male (\%) & $114(76.0)$ & $118(78.7)$ & $89(71.2)$ & $93(74.4)$ & $67(39.8)$ & $73(68.2)$ & $78(70.2)$ \\
\hline Diabetes mellitus(n\%) & NA & NA & $29(23.2)$ & $24(19.2)$ & $18(16.1)$ & 21(19.6) & $19(17.1)$ \\
\hline Hypertension(n\%) & $71(47.3)$ & $69(46.0)$ & NA & NA & $59(52.7)$ & $69(64.5)$ & $42(37.8)$ \\
\hline LVEF (\%) & $60.10 \pm 6.88$ & $60.11 \pm 7.77$ & NA & NA & $9(8.0)$ & $5(4.7)$ & $13(11.7)$ \\
\hline \multicolumn{8}{|l|}{ Drugs } \\
\hline \multirow[t]{2}{*}{ ACEI/ARB (\%) } & $132(88.0)$ & $134(89.3)$ & $111(88.8)$ & $111(88.8)$ & $46(41.1)$ & $56(52.3)$ & $56(50.5)$ \\
\hline & $118(78.7)$ & $116(77.3)$ & $111(88.8)$ & $112(89.6)$ & & & \\
\hline
\end{tabular}




\begin{tabular}{|c|c|c|c|c|c|c|c|}
\hline$\beta$-block (\%) & & & & & $93(83.8)$ & $80(74.8)$ & $81(73.0)$ \\
\hline Statin (\%) & & & & & NA & NA & NA \\
\hline Clopidogrel (\%) & $150(100)$ & $150(100)$ & NA & NA & $112(100)$ & $107(100)$ & $111(100)$ \\
\hline $\mathrm{CCB}$ & $\mathrm{NA}$ & NA & $21(16.8)$ & $16(12.8)$ & NA & NA & NA \\
\hline Aspirin, n (\%) & $150(100)$ & $150(100)$ & NA & NA & $112(100)$ & $107(100)$ & $111(100)$ \\
\hline CAG, n (\%) & NA & NA & NA & NA & NA & NA & NA \\
\hline PCI, n (\%) & NA & NA & NA & NA & NA & NA & NA \\
\hline
\end{tabular}


BNP: brain natriuretic peptide; SD: standard deviation; LVEF: left ventricular ejection fraction; ACEI: angiotension converting enzyme inhibitors;

ARB: angiotensin receptor blocker; CCB: calcium channel blockers; CAG: coronary angiography; PCI: percutaneous coronary intervention. 
Figure 4

The surface under the cumulative ranking curve (SUCRA) for all interventions in the study

(A) The SUCRA of all agents for decreasing the incidence of CIN. (B) The SUCRA of all drugs for the efficacy of reducing the change of SCr levels. The size of SUCRA is proportional to the efficacy of the treatment. $a=$ intravenous saline; $b=$ nitroglycerin; $c=B N P ; d=$ usual-dose nicorandil; e=double-dose nicorandil.

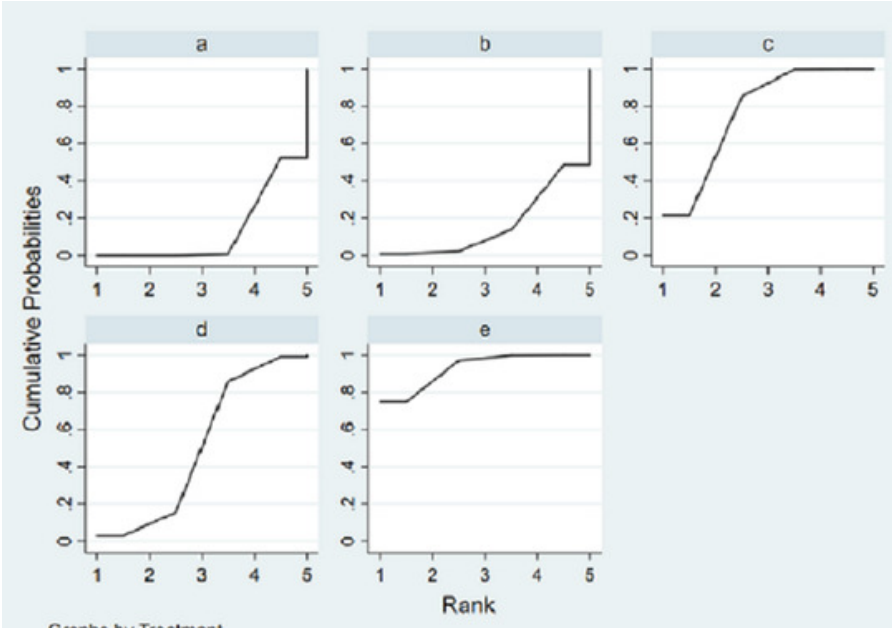

Graphs by Treatment

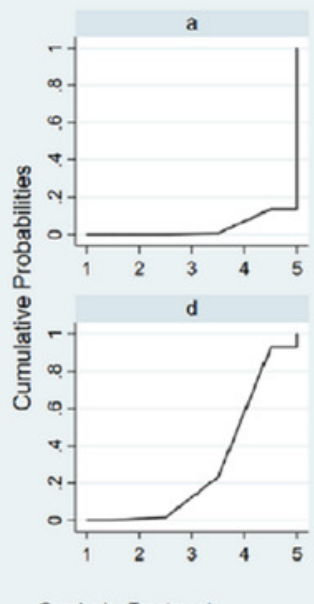

Graphs by Treatment

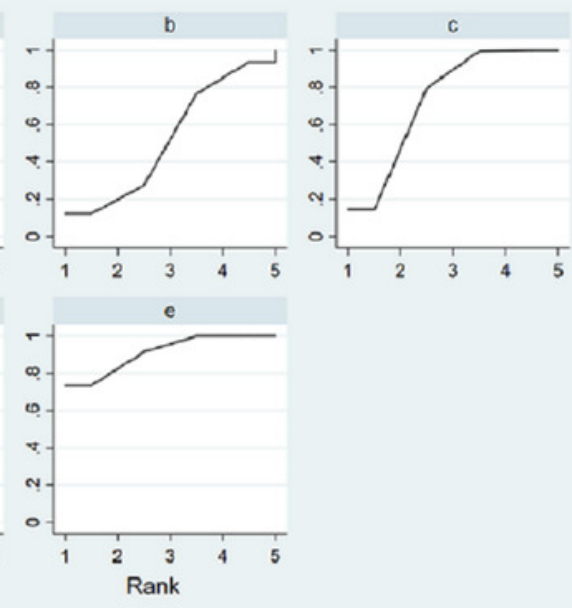

B 


\section{Figure 5}

Funnel plot of the treatment in the study

(A) Funnel plot for the assessment of the occurrence of CIN. (B) Funnel plot for the efficacy of reducing the change of $\mathrm{SCr}$ levels. The red line represents the null hypothesis that there is no significant difference between the study-specific effect sizes and the respective comparisonspecific pooled effect estimates. The purple line is the regression line. Different colors correspond to different comparisons. $a=$ intravenous saline; $b=$ nitroglycerin; $c=B N P$; $d=$ usual-dose nicorandil; e=double-dose nicorandil.

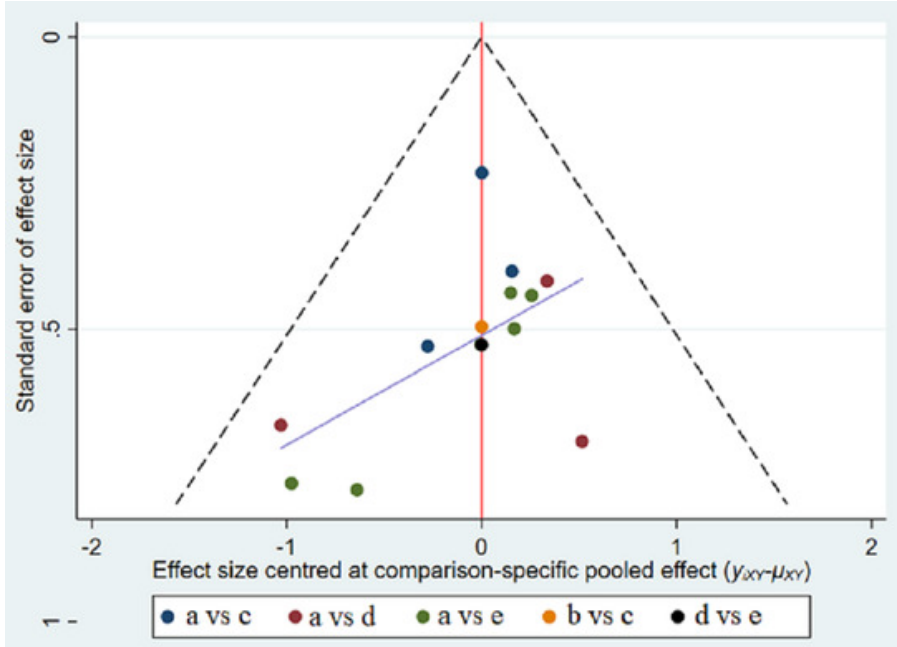

A

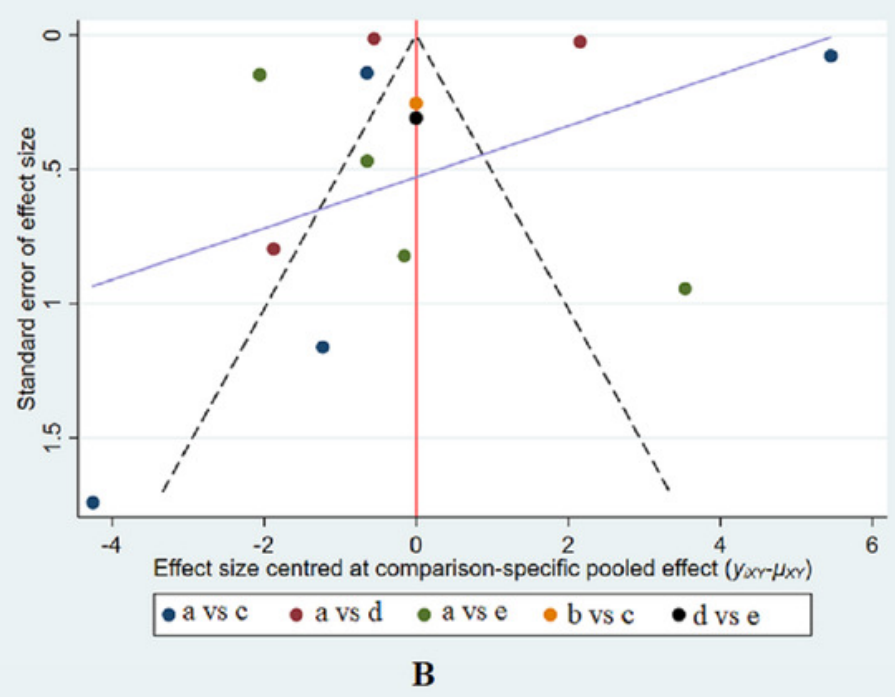

